\title{
Las sucursales en Perú y la aplicación de la Decisión 578 de la Comunidad Andina de Naciones
}

\author{
Branch offices Peru and the application of the Decision 578 \\ from the Andean Community of Nations
}

Gonzalo Alonso Escalante Alpaca

Universidad Católica San Pablo, Arequipa, Perú • gaescalante@ucsp.edu.pe

\section{Resumen}

Este artículo analiza el tratamiento aplicable, conforme a la Decisión 578 de la Comunidad Andina de Naciones (CAN), «Régimen para evitar la doble tributación y prevenir la evasión fiscal», a las sucursales ubicadas en Perú de empresas domiciliadas, para efectos fiscales, en alguno de los países conformantes de la CAN con el objetivo de establecer, en forma clara, el tratamiento de estas entidades según la norma tributaria peruana. Para ello se realiza una revisión de las implicancias generadas por la Decisión 578 respecto a estas sucursales, considerando la jurisprudencia del Tribunal Fiscal (TF) y la doctrina especializada. Se concluye que estas sucursales se encuentran gravadas en Perú solamente por sus rentas de fuente peruana, por lo que las rentas obtenidas en el extranjero no tributarán en Perú. En en el caso de los dividendos distribuidos por las sucursales, se concluye que no existe la posibilidad de una doble imposición, por considerarse a estos ingresos como exonerados en el país donde se encuentra domiciliada la matriz.

Palabras clave: sucursal, Decisión 578, CAN, doble imposición, impuesto a la renta.

\section{Abstract}

This article analyzes the treatment that applies according to the Decision 578 of the Andean Community of Nations (CAN), "Regime to avoid the double taxation and prevent tax evasion", to the branches located in Peru of companies domiciled, for tax purposes, on any of the other countries that are members of CAN to establish the treatment that applies to such entities accor-

illustro • Universidad Católica San Pablo, Arequipa • Vol. 11, 2020, 49-66 • ISSN 2311-4126 // e-ISSN 2710-2440 
ding to the Peruvian tax law. This analysis considers the implications generated by Decision 578 on such branches, taking into consideration the jurisprudence of the Peruvian Tax Court (TF) and the comments of the specialized doctrine. We conclude that these branches are considered as taxpayers in Peru but only regarding the income obtained in this country, therefore the income obtained abroad is considered as non-taxable in Peru. On the matter of the distribution of dividends, the conclusion is that there is no risk of double taxation, because such income is considered as non-taxable in the country where the mother company is domiciled.

Keywords: branch, Decision 578, CAN, double taxation, income tax.

\section{Introducción}

Perú, en tanto Estado miembro de la Comunidad Andina de Naciones (CAN), debe incorporar dentro de su legislación las normas emitidas por este órgano, considerándolas como parte del derecho nacional.

La Decisión 578 tiene por objetivo evitar la doble imposición sobre los ingresos generados en alguno de los países conformantes de la CAN (Perú, Colombia, Ecuador y Bolivia) por agentes económicos domiciliados en estos países. Resulta entonces necesario establecer cuál es el tratamiento aplicable a las sucursales ubicadas en Perú, cuya matriz está domiciliada en algún otro país miembro de la CAN.

Para ello, se van a analizar los alcances de las disposiciones contenidas en la Decisión 578 respecto a los beneficios empresariales obtenidos mediante las sucursales ubicadas en un país de la CAN y cuya matriz sea una compañía domiciliada en algún otro país que sea, a su vez, miembro de esta comunidad. También se revisa el tratamiento aplicable a los dividendos generados por estas sucursales, así como las reglas aplicables a dichas entidades conforme a la normativa peruana. Para ello, nos remitimos en estricto a la Ley del Impuesto a la Renta Peruana (LIR). Finalmente, se analizará cuál es el tratamiento aplicable a las sucursales considerando una interpretación sistemática de la LIR y la Decisión 578.

No se ha identificado algún estudio que analice, en forma específica, el tratamiento aplicable a las sucursales en Perú de empresas domiciliadas en algún país de la CAN, buscando realizar una interpretación sistemática de la norma tributaria peruana con la Decisión 578 a efecto de establecer si existe alguna contingencia en la aplicación de ambas, o la forma en la que estas regulaciones se complementan para así evitar que se configure una doble imposición, tanto por las rentas empresariales como por los dividendos generados en las sucursales.

Dentro de este análisis, nuestra hipótesis establece que, en tanto las sucursales tributan en Perú solamente sobre sus rentas empresariales de fuente peruana, la Decisión 578 implica que el país donde esté constituida la matriz considerará a tales ingresos como exonerados, siendo además que las sucursales ubicadas en Perú tributan únicamente sobre sus rentas de fuente peruana; y en lo que respecta a los dividendos distribuidos por estas sucursales (calculados únicamente sobre la base de sus ingresos de fuente peruana), tenemos que sobre estos no existe riesgo de doble imposición, pues, en aplicación de la 
Decisión 578, tales ingresos se consideran como exonerados en el país donde se encuentra ubicada la matriz.

Así pues, se desarrolla una investigación jurídico-exploratoria sobre la base de la Decisión 578 y sus implicancias respecto a las sucursales, considerando a su vez el tratamiento aplicable a estas por la norma tributaria peruana. Se emplea, además, el método hipotético-deductivo para establecer la veracidad o no de la hipótesis descrita.

El estudio está dividido en tres apartados: el primero versa sobre el tratamiento aplicable a los beneficios empresariales y a los dividendos según los alcances de la Decisión 578, el segundo contiene un análisis de la regulación doméstica peruana sobre las actividades desarrolladas a través de sucursales y, finalmente, el tercer apartado está vinculado a establecer la existencia de puntos coincidentes o no entre el tratamiento previsto en la Decisión 578 y la legislación del Impuesto a la Renta (IR).

\section{Alcances de la Decisión 578}

\subsection{Beneficios empresariales (rentas)}

La Decisión 578 tiene como objetivo limitar el ejercicio de la facultad de recaudación tributaria de los Estados conformantes de la CAN, de forma tal que las rentas generadas por una persona o empresa en un determinado país miembro se encuentren sometidas a imposición únicamente en dicho territorio, con lo cual el país del domicilio (distinto al país en el cual se generó la renta) del sujeto generador debe considerar a dichas rentas como exoneradas para efectos de la determinación del impuesto a pagar por el contribuyente en cuestión. Se otorga así prevalencia al criterio de la fuente para establecer la jurisdicción que tendrá la potestad de gravar el hecho generador de rentas.

Al respecto tenemos que el artículo 1 de la Decisión 578 dispone lo siguiente:

\section{Ámbito de Aplicación}

La presente Decisión es aplicable a las personas domiciliadas en cualquiera de los Países Miembros de la Comunidad Andina, respecto de los impuestos sobre la renta y sobre el patrimonio. Se aplica principalmente a los siguientes:

En Bolivia, Impuesto a la renta.

En Colombia, Impuesto a la renta.

En el Ecuador, Impuesto a la renta.

En el Perú, Impuesto a la renta.

Las normas previstas en esta Decisión tienen por objeto evitar la doble tributación de unas mismas rentas o patrimonios a nivel comunitario.

La presente Decisión se aplicará también a las modificaciones que se introdujeran a los referidos impuestos y a cualquier otro impuesto que, en razón de su base gravable o materia imponible, fuera esencial y económicamente análogo a los anteriormente citados y que fuere establecido por cualquiera de los Países Miembros con posterioridad a la publicación de esta Decisión. (CAN, 2004).

Sobre el particular, el TF en la Resolución 03256-3-2013 señala:

Que el artículo 1 de la Decisión 578, establece que es aplicable a las personas 
domiciliadas en cualquiera de los países miembros respecto de los impuestos sobre la renta y sobre el patrimonio, puntualizando que se aplica, entre otros, en el Perú y en Ecuador; respecto del Impuesto a la Renta; que su artículo 3 señala que independientemente de la nacionalidad o domicilio de las personas, las rentas de cualquier naturaleza que éstas obtuvieren, sólo serán gravables en el país miembro en que tales rentas tengan su fuente productora, salvo los casos de excepción previstos en esta Decisión, y que por tanto, los demás países miembros que, de conformidad con su legislación interna, se atribuyen potestad de gravar las referidas rentas, deberán considerarlas como exoneradas, para los efectos de la correspondiente determinación del impuesto a la renta o sobre el patrimonio. (Resolución del Tribunal Fiscal 03256-3-2013, 2013).

El artículo 3 de la Decisión 578 señala que:

\section{Jurisdicción Tributaria}

Independientemente de la nacionalidad o domicilio de las personas, las rentas de cualquier naturaleza que éstas obtuvieren, sólo serán gravables en el País Miembro en el que tales rentas tengan su fuente productora, salvo los casos de excepción previstos en esta Decisión.

Por tanto, los demás Países Miembros que, de conformidad con su legislación interna, se atribuyan potestad de gravar las referidas rentas, deberán considerarlas como exoneradas, para los efectos de la correspondiente determinación del impuesto a la renta o sobre el patrimonio. (CAN, 2004).
A su vez, el artículo 6 del mismo cuerpo normativo dispone que:

\section{Beneficios de las empresas}

Los beneficios resultantes de las actividades empresariales sólo serán gravables por el País Miembro donde éstas se hubieren efectuado.

Se considerará, entre otros casos, que una empresa realiza actividades en el territorio de un País Miembro cuando tiene en éste:

a. Una oficina o lugar de administración o dirección de negocios;

b. Una fábrica, planta o taller industrial o de montaje;

c. Una obra de construcción;

d. Un lugar o instalación donde se extraen o explotan recursos naturales, tales como una mina, pozo, cantera, plantación o barco pesquero;

e. Una agencia o local de ventas;

f. Una agencia o local de compras;

g. Un depósito, almacén, bodega o establecimiento similar destinado a la recepción, almacenamiento o entrega de productos;

h. Cualquier otro local, oficina o instalación cuyo objeto sea preparatorio o auxiliar de las actividades de la empresa;

i. Un agente o representante. 
Cuando una empresa efectúe actividades en dos o más Países Miembros, cada uno de ellos podrá gravar las rentas que se generen en su territorio, aplicando para ello cada País sus disposiciones internas en cuanto a la determinación de la base gravable como si se tratara de una empresa distinta, independiente y separada, pero evitando la causación de doble tributación de acuerdo con las reglas de esta Decisión. Si las actividades se realizaran por medio de representantes o utilizando instalaciones como las indicadas en el párrafo anterior, se atribuirán a dichas personas o instalaciones los beneficios que hubieren obtenido si fueren totalmente independientes de la empresa. (CAN, 2004).

Al respecto debemos agregar que la Administración Tributaria señala lo siguiente:

De acuerdo con el primer párrafo del artículo 1 de la Decisión 578, esta es aplicable a las personas domiciliadas en cualquiera de los Países Miembros de la Comunidad Andina, respecto de los impuestos sobre la renta y sobre el patrimonio.

De otro lado, como regla general, el artículo 6 de dicho instrumento dispone que los beneficios resultantes de las actividades empresariales sólo serán gravables por el País Miembro donde éstas se hubieran efectuado. (Sunat, Informe 008-2012-SUNAT/2B0000, 2012).

De la normativa y los pronunciamientos citados obtenemos que la Decisión 578 busca evitar que un sujeto generador de rentas empresariales, que sea domiciliado en alguno de los países miembros de la $\mathrm{CAN}$, se encuentre sujeto a gravamen en dos oportunidades (ante dos jurisdicciones conformantes de la CAN) respecto a un mismo ingreso o hecho generador de renta. Nos explicamos: si una compañía que se encuentra domiciliada, por ejemplo, en Colombia, comercializa productos en Perú a través de algún establecimiento como los descritos en el artículo 6 de la Decisión 578 previamente citado, tenemos que los beneficios obtenidos como consecuencia de dicha actividad se encontrarán gravados con el IR únicamente en Perú, debiendo Colombia considerar a estos rendimientos como exonerados para efectos del IR.

Se crea así una exención al ejercicio de la facultad de recaudación por parte del fisco colombiano respecto a estas rentas, pues la Decisión 578 dispone que solamente se podrán afectar en el país en el que se generó el ingreso. Evitándose de este modo que el ingreso obtenido por la comercialización de bienes se encuentre gravado en ambas jurisdicciones.

Entonces, tenemos que, en aplicación de la Decisión 578, el elemento condicionante para que las rentas de esta empresa puedan ser gravadas con el IR en Perú es que la actividad comercial se haga efectiva mediante alguno de los establecimientos antes mencionados que se ubique físicamente dentro del territorio peruano, en cuyo caso la afectación aplicable sería únicamente respecto al IR en nuestro país por los rendimientos que dicho establecimiento genere. De ser este el caso, resulta necesario que el establecimiento de una empresa colombiana utilizada para el desarrollo de operaciones en Perú cuente con un Certificado de Residencia emitido por el fisco peruano, de forma tal que le resulte aplicable la Decisión 578 y como consecuencia de ello, sus rentas no sean sujetas a gravamen también por el fisco colombiano. 
Sobre lo antes señalado tenemos que la Administración Tributaria ha indicado lo siguiente:

Con relación a la primera consulta, cabe indicar que conforme con lo dispuesto en el artículo 2 del Decreto Supremo 090-2008-EF, el Certificado de Residencia emitido por la entidad competente de un Estado con el cual el Perú ha celebrado un CDI [convenio contra la doble imposición], tiene por finalidad acreditar la calidad de residente en ese Estado a fin de poder hacer uso de los beneficios contemplados en el CDI.

Agrega la norma que, si el sujeto residente del otro Estado no presenta el Certificado de Residencia al momento de la retención, el agente de retención deberá efectuarla sin considerar los beneficios contemplados en el CDI.

Como se aprecia, el Certificado de Residencia en análisis tiene por finalidad acreditar la calidad de residente en un Estado con el cual el Perú tiene suscrito un CDI a fin de poder hacer uso de los beneficios contemplados en el mismo. (Sunat, Informe 094-2015-SUNAT/5D0000, 2015).

El Certificado de Residencia resulta entonces una formalidad necesaria para que la Decisión 578 surta efectos e impida la doble imposición por concepto de IR en dos jurisdicciones distintas respecto a un mismo hecho imponible.

\subsection{Tratamiento aplicable a los dividendos}

El artículo 11 de la Decisión 578 dispone que:

\section{Dividendos y participaciones}

Los dividendos y participaciones sólo serán gravables por el País Miembro donde estuviere domiciliada la empresa que los distribuye.

El País Miembro en donde está domiciliada la empresa o persona receptora o beneficiaria de los dividendos o participaciones, no podrá gravarlos en cabeza de la sociedad receptora o inversionista, ni tampoco en cabeza de quienes a su vez sean accionistas o socios de la empresa receptora o inversionista. (CAN, 2004). 
Del texto citado se obtiene que es imprescindible que se identifique cuál es la condición domiciliaria del sujeto que distribuye los dividendos para efecto de establecer qué jurisdicción resulta competente para gravar dicha renta, dado que, si estos son distribuidos por una sucursal domiciliada en un país de la CAN, el otro país miembro donde se encuentre domiciliado el beneficiario del dividendo (matriz de la sucursal) deberá considerar a este ingreso como exonerado.

\section{Tratamiento fiscal de las sucursales según la Ley del Impuesto a la Renta (LIR)}

\subsection{Reglas aplicables a los beneficios empre- sariales de las sucursales conforme a la LIR}

El artículo 6 de la LIR, en su segundo párrafo, dispone que:

En caso de contribuyentes no domiciliados en el país, de las sucursales, agencias u otros establecimientos permanentes de empresas unipersonales, sociedades y entidades de cualquier naturaleza constituidas en el exterior a que se refiere el inciso e) del artículo 7, el impuesto recae solo sobre las rentas gravadas de fuente peruana. (Texto Único Ordenado de la Ley del Impuesto a la Renta, 2004).

A su vez, el inciso e) del artículo 7 de la LIR dispone que se consideran domiciliadas en el país:

Las sucursales, agencias u otros establecimientos permanentes en el Perú de empresas unipersonales, sociedades y entidades de cualquier naturaleza constituidas en el exterior, en cuyo caso la condición de domiciliada alcanza a la sucursal, agen- cia u otro establecimiento permanente, en cuanto a su renta de fuente peruana. (Texto Único Ordenado de la Ley del Impuesto a la Renta, 2004).

Cabe indicar que el texto actual del segundo párrafo del artículo 6 de LIR y el inciso e) del artículo 7 del mismo cuerpo normativo han sido modificados mediante el Decreto Legislativo 1424 (DL 1424), a través del cual se han recogido las recomendaciones de la acción 7 del plan BEPS (Base Erosion and Profit Shifting, «Erosión de las bases imponibles y traslado de beneficios», traducido al español) de la OCDE (Organización para la Cooperación y el Desarrollo Económicos), organización a la cual nuestro país pretende ingresar en un mediano plazo. Esta acción busca combatir el uso indebido de la figura de los establecimientos permanentes (EP) para evitar la afectación en el lugar de la fuente de la renta. Siendo así, nuestra legislación ha sido modificada para incluir dentro de la definición de los EP a aquellos establecimientos temporales con el objetivo de atribuirles la condición de sujetos domiciliados para efectos fiscales, los cuales estarán sujetos a imposición en Perú únicamente respecto a sus rentas de fuente peruana.

Ahora bien, conforme a la legislación peruana tenemos que las sucursales tienen un tratamiento especial, pues se trata de contribuyentes domiciliados en Perú, respecto a los cuales no resulta aplicable una afectación sobre las rentas de fuente mundial, sino que se circunscribe el gravamen del IR únicamente sobre las rentas de fuente peruana. Es un tratamiento distinto al dispuesto para el resto de los contribuyentes domiciliados que se encuentran afectos en Perú sobre la totalidad de las rentas de fuente mundial, sin que resulte 
aplicable discriminación alguna que implique algún supuesto eximente de tributación, salvo los que pudieran estar recogidos en alguno de los Convenios contra la Doble Imposición (CDI) suscritos por Perú.

En este sentido, tenemos que el inciso h) del artículo 14 de la LIR establece que se consideran como domiciliados en Perú: «Las sucursales, agencias o cualquier otro establecimiento permanente en el país de empresas unipersonales, sociedades y entidades de cualquier naturaleza constituidas en el exterior» (Texto Único Ordenado de la Ley del Impuesto a la Renta, 2004).

Sobre el particular, la Administración Tributaria dispone lo siguiente:

Asimismo, el artículo 14 de la referida ley indica que para los efectos de esta se considerarán personas jurídicas, entre otras, a las sucursales, agencias o cualquier otro establecimiento permanente en el país de empresas unipersonales, sociedades y entidades de cualquier naturaleza constituidas en el exterior.

Como se puede apreciar, la Ley del Impuesto a la Renta ha establecido, para efectos de este impuesto, una personería jurídico tributaria propia $-\mathrm{y}$ distinta de su matriz - para las sucursales, agencias o cualquier otro establecimiento permanente establecidos en el país de personas jurídicas no domiciliadas.

Además, siendo ello así, toda vez que la sucursal establecida en otro país no tiene personería jurídica distinta de la de su matriz, resulta evidente, entonces, que la personería jurídico tribu- taria propia de la sucursal ubicada en el Perú es también distinta respecto de aquella otra sucursal. (Sunat, Informe 127-2016-SUNAT/5D0000, 2016).

Entonces, conforme a la normativa tributaria peruana las sucursales se constituyen como EP, respecto a los cuales para fines fiscales se ha creado una ficción jurídica que le otorga una personería jurídica distinta a la de su matriz, con lo que la sucursal resulta susceptible de atribución de obligaciones y derechos frente al fisco peruano en forma independiente y autónoma.

Este tratamiento independiente atribuible por la legislación tributaria peruana a las sucursales parte de la aplicación de la teoría de independencia absoluta, sobre la base de la cual las sucursales son entendidas como entes jurídicos independientes de su matriz, de forma tal que las operaciones llevadas a cabo entre estas dos partes se consideran como desarrolladas entre dos particulares.

Yáñez Salgado (2010) desarrolla la teoría de la independencia absoluta indicando que:

Bajo esta teoría se equiparán las relaciones de los EP, terceros y sus Casas Matrices como verdaderas relaciones jurídicas efectuadas entre terceros para asegurar el principio de empresa independiente.

Desde esta perspectiva para fines fiscales, la Casa Matriz y su EP son considerados como autónomos y distintos centros de referencia y de imputación de obligaciones jurídicas, a semejanza de lo que se verificaría entre dos sujetos autónomos, aunque vinculados entre sí por un interés económico común. 
Continúa la autora, señalando que «dicha teoría dispone que el tratamiento tributario en relación con los ingresos no difiere de aquel tratamiento aplicable a una empresa subsidiaria legalmente independiente y establecida en el país» (Yáñez Salgado, 2010).

Es necesario, pues, entender la real magnitud del planteamiento recogido en esta teoría, ya que nos permite tener una clara comprensión del objetivo perseguido por la norma tributaria peruana que busca gravar a las sucursales únicamente por las rentas consideradas de fuente peruana, tomando como justificación para ello la vinculación que tiene que existir entre la renta generada y el territorio peruano. Se consigna así un tratamiento fiscal distinto al aplicable para la matriz no domiciliada.

En este orden de ideas, Fernández-Dávila Mendoza (2010) señala lo siguiente:

En efecto, el legislador fiscal en el Perú como en la gran mayoría de países, ha optado por darle independencia y personería jurídica propia a las unidades independientes de negocio de sociedades extranjeras (establecimientos permanentes) dentro de los cuales, el más representativo de este tipo de agentes económicos, son las sucursales de sociedades; otorgándoles un tratamiento independiente del que pudieran recibir sus casas matrices.

Así pues, en tanto existe esta independencia entre la matriz y su sucursal domiciliada en Perú, puede darse el caso de que esta matriz genere rentas en Perú por transacciones que realice en forma directa y sin intervención de su sucursal. En este caso, los ingresos que genere esta matriz se encontrarán sujetos al IR en Perú al configurarse como rentas de fuente peruana y, por otro lado, la sucursal tributará en Perú por los ingresos que obtenga como consecuencia del desarrollo de sus actividades económicas. Ambas entidades, tanto la matriz como la sucursal, son consideradas como contribuyentes separados para efectos fiscales según la normativa peruana.

Cabe mencionar que el tratamiento en materia tributaria a las sucursales también se distingue claramente del tratamiento recogido en la norma societaria peruana.

Sobre este extremo tenemos que el artículo 396 de la Ley General de Sociedades - Ley 26887 (LGS) conceptualiza a la sucursal de la siguiente manera:

Es sucursal todo establecimiento secundario a través del cual una sociedad desarrolla, en lugar distinto a su domicilio, determinadas actividades comprendidas dentro de su objeto social. La sucursal carece de personería jurídica independiente de su principal. Está dotada de representación legal permanente y goza de autonomía de gestión en el ámbito de las actividades que la principal le asigna, conforme a los poderes que otorga a sus representantes. (Ley General de Sociedades, 1997).

El artículo 397 del mismo cuerpo normativo señala a su vez que: «La sociedad principal responde por las obligaciones de la sucursal. Es nulo todo pacto en contrario» (Ley General de Sociedades, 1997).

Al respecto, Pérez Montenegro (2010) refiere que:

La sucursal carece de personería jurídica independiente de su principal. Goza de 
autonomía de gestión en el ámbito de las actividades que la principal le asigna, conforme a los poderes que otorga a sus representantes; ello de conformidad con el artículo 396 de la LGS.

La casa matriz o sociedad principal y la sucursal son dos establecimientos físicamente distintos, pero ello no conlleva a la creación de una personería jurídica diferente para cada uno de ellos para efectos societarios. Si bien las sucursales son establecimientos permanentes que permiten la dispersión territorial de la casa matriz, mantiene una unidad jurídica como sujeto de derecho con esta última.

Elías Laroza (2015), por su parte, indica que:

El artículo 396 define a las sucursales como establecimientos secundarios a través de los cuales una sociedad desarrolla, fuera del domicilio social, actividades comprendidas dentro de su objeto social. Estos establecimientos se caracterizan por no estar dotados de personería jurídica distinta de la principal, por tener representantes legales permanentes y por desarrollar sus actividades dentro de una relativa autonomía de gestión.

El mismo autor señala que:

En concordancia con ello, el artículo 397 establece que la sociedad principal responde por las obligaciones de la sucursal. Las obligaciones contraídas a través de la sucursal no dejan de ser obligaciones de la sociedad y se encuentran respaldadas por la totalidad del patrimonio de esta, inclusive por el de la sucursal, con prescindencia del hecho de que tal patrimonio se encuentre asignado exclusivamente a la sucursal o no. Lo mismo ocurre, en el caso inverso, con todas las obligaciones de la sociedad con respecto a los bienes de la sucursal, que también responden en forma ilimitada. (Elias Laroza, 2015).

Así, pues, tenemos que conforme a la norma societaria peruana las sucursales no se constituyen como sujetos susceptibles de la atribución de derechos y obligaciones en forma independiente de su matriz. Es un tratamiento diametralmente distinto al de la norma tributaria peruana, según lo detallado previamente.

\subsection{Distribución de dividendos por las sucursales}

Conforme al inciso e) del artículo 56 de la LIR, resulta aplicable una tasa del 5\% a los dividendos, además de otras formas de distribución de utilidades que efectúen las sucursales domiciliadas en Perú a favor de personas jurídicas no domiciliadas.

En el segundo párrafo del mismo inciso se establece que, en el caso de sucursales u otros tipos de EP en el país de empresas unipersonales, sociedades y entidades de cualquier naturaleza constituidas en el exterior, se entenderán distribuidas las utilidades en la fecha de vencimiento del plazo para la presentación de la Declaración Jurada anual del IR, considerándose como monto de la distribución la renta disponible a favor del titular del exterior. La base de cálculo comprenderá la renta neta de la sucursal u otro tipo de EP incrementada por los ingresos por intereses exonerados y dividendos, además de otras formas de distribución de utilidades u otros conceptos disponibles que se hubiese generado en el ejercicio, menos el monto del impuesto pagado por concepto de rentas empresariales. 
Respecto a este punto, tenemos que la Administración Tributaria concluye que:

En relación con los dividendos provenientes de sucursales u otro tipo de establecimientos permanentes de personas jurídicas no domiciliadas en el país a que se refiere el segundo párrafo del inciso e) del artículo $56^{\circ} \mathrm{de}$ la Ley del Impuesto a la Renta:

1. La base de cálculo del Impuesto a la Renta está compuesta por la renta neta de dicha sucursal o establecimiento permanente, a la cual se le debe adicionar los ingresos por intereses exonerados y dividendos $\mathrm{u}$ otras formas de distribución de utilidades u otros conceptos disponibles, generados en el ejercicio, menos el monto del Impuesto a la Renta pagado por dicha sucursal o establecimiento.

2. Para determinar dicha base de cálculo no corresponde que se compensen las pérdidas de ejercicios anteriores que registren tales sucursales o establecimientos anexos. (Sunat, Informe 066-2014-SUNAT/4B0000, 2014).

Tenemos, entonces, que la normativa peruana recoge una presunción sobre la base de la cual las utilidades obtenidas por las sucursales en Perú se consideran distribuidas en la fecha de vencimiento del plazo para la presentación de la Declaración Jurada anual del IR. Siendo que en este momento deberá aplicarse la retención correspondiente y proceder con su pago a favor del fisco. Ello sin perjuicio de que los dividendos no sean distribuidos en forma efectiva a la matriz en esa fecha.

\section{Tratamiento fiscal aplicable a las sucursales conforme a lo previsto en la LIR y la Decisión 578}

\subsection{Respecto a los beneficios empresariales generados en un país miembro de la CAN}

El TF analizó los alcances de la aplicación de la Decisión 578 respecto a la sucursal de una empresa domiciliada en Ecuador que se encontraba ubicada en Perú. Como consecuencia del análisis efectuado por el órgano resolutor, se llegó a la conclusión de que la Decisión 578 no resulta aplicable para el caso de las sucursales sobre la base de los siguientes argumentos:

Que al respecto, toda vez que por la condición de domiciliada en el Perú, las sucursales, agencias u otro establecimiento permanente de 
una empresa no domiciliada tributan únicamente por sus rentas de fuente peruana y no por sus rentas de fuente extranjera, se tiene que éstas, no tributan por las rentas provenientes de los países miembros de la Comunidad Andina.

Que en consecuencia, toda vez que la Decisión 578 tiene como objetivo eliminar la doble imposición tributaria entre los países miembros de la Comunidad Andina, estas disposiciones no les son aplicables a las sucursales consideradas domiciliadas en el Perú, dado que éstas tributan únicamente por rentas de fuente peruana y no a su vez por rentas de fuente extranjera. (Resolución del Tribunal Fiscal 02988-1-2017, 2017).

Continúa la resolución citada indicando lo siguiente:

Que toda vez que la recurrente es una sucursal de una empresa constituida en el exterior, que no tributa por rentas de fuente extranjera, no corresponde que se le emita el Certificado de Residencia, dado que el referido certificado, que se presentaría en el Ecuador (país con el que el Perú suscribió la Decisión 578), tiene como presupuesto de hecho el evitar la doble imposición tributaria, no obstante, conforme se indicó, la recurrente en su condición de sucursal de una empresa no domiciliada está afecta únicamente a rentas de fuente peruana. (Resolución del Tribunal Fiscal 02988-1-2017, 2017).

$\mathrm{Al}$ respecto, debemos indicar que consideramos que el razonamiento esgrimido por el $\mathrm{TF}$ en la resolución citada no resulta preciso, pues si bien la sucursal de una empresa extranjera tributa en Perú únicamente sobre sus rentas de fuente peruana, es necesario que los ingresos obtenidos por esta entidad sean considerados como exonerados por el país donde se encuentra ubicada la matriz, lo cual se consigue con la emisión del correspondiente Certificado de Residencia. Certificado que permite acreditar que la fuente de la renta está ubicada en Perú, sustentando así su condición de ganancia exonerada para el país donde se encuentre ubicada la matriz, considerando que la matriz está en otro de los países de la CAN.

Nos explicamos; en primer término, debemos considerar que la existencia de una sucursal en Perú implica el cumplimiento de lo dispuesto en el artículo 6 de la Decisión 578, previamente mencionado, considerándose que los ingresos tienen su fuente en este país. En tal sentido, en el momento de generarse la renta por la sucursal domiciliada en Perú, no existe riesgo de doble imposición pues esta entidad solamente tributa en nuestro país por sus rentas de fuente peruana; debiendo la matriz reconocer la vinculación de la renta con nuestro país, lo cual se sustenta en el Certificado de Residencia que va a permitir que las ganancias no se encuentren nuevamente gravados con el IR en esta jurisdicción. Resultando necesaria la emisión del Certificado de Residencia para que la Decisión 578 surta efectos al limitar la facultad recaudatoria del país donde domicilia la matriz.

Respecto a la vinculación que debe existir entre la generación de ingresos y un territorio para que resulte aplicable la carga impositiva regulada conforme a la norma doméstica, como se da en el caso de las sucursales ubicadas en Perú, Durán Rojo (2008) refiere que:

En ese sentido, la actual tendencia sobre tributación de SND [sujeto no domiciliado] 
ya no hace referencia única a la territorialidad de un hecho para determinar la potestad de un Estado para gravar las rentas generadas por tales sujetos en la consecución de su actividad; sino que, tal derecho se fundamenta en la relación existente entre el Estado y la capacidad económica revelada de un hecho, aun cuando en algunos casos se realice efectivamente dentro de su territorio. Ello debido a que la fuente es considerada como el lugar del cual se obtiene la renta, siendo ésta el fruto que proviene de un ámbito que por sus diversos factores permite que se haya obtenido de manera circunstancial o episódica.

De acuerdo a lo antes expuesto, para que un Estado establezca mediante su legislación interna que determinada riqueza obtenida por un SND se encuentra gravada, debe existir conexión entre el hecho considerado gravado y dicho Estado como lugar de la «fuente». Ello se fundamenta en la pertenencia económica o cuasi personal del contribuyente a dicho Estado, las cuales resultan de su participación suficientemente intensa en la producción, tráfico o consumo de la riqueza de ese Estado; y por las ventajas que recibe del mismo para la realización de su actividad que terminará generando una determinada riqueza. Así, la referida tributación del SND debe encontrarse limitada a la efectiva ganancia obtenida de su actividad en dicho Estado, es decir, debe ser respecto de aquellos que efectivamente haya obtenido en el mismo (criterio objetivo) y por tal no deberá tomarse en cuenta criterios subjetivos tales como aptitud y capacidad económica.

En el caso de las sucursales domiciliadas en Perú, tenemos que es justamente el hecho de que las rentas se hayan producido en este país, lo que va a significar que se alcance a evitar la doble imposición sobre las mismas al restringirse la facultad recaudatoria del país donde esté domiciliada la matriz. Reiteramos, en este sentido, que la sola vinculación entre la fuente de rentas y el domicilio de las sucursales por sí misma no implica que el país donde está ubicada la matriz considere las rentas de la sucursal como exoneradas en aplicación de la Decisión 578, por lo que deberá acreditarse, además, mediante un Certificado de Residencia, que la fuente de la renta está en Perú conforme se mencionó previamente.

Cabe mencionar a su vez que, considerando el criterio de la vinculación entre la fuente y la facultad de un determinado país para gravar y recaudar tributos respecto a un ingreso, la legislación tributaria interna de Perú exime de afectación a cualquier renta que una sucursal pudiera generar en el extranjero, pues no existe vinculación alguna entre esta y el territorio peruano. Debemos entender entonces que, conforme a la 
legislación tributaria peruana, los ingresos de fuente extranjera de las sucursales domiciliadas en Perú se constituyen en ingresos inafectos para el IR, por encontrarse fuera del ámbito de aplicación de dicho tributo.

\subsection{Respecto a la distribución de dividendos por las sucursales en Perú de empresas cuya matriz está domiciliada en otro país de la CAN}

Conforme a lo comentado previamente, nuestro ordenamiento recoge una ficción jurídica mediante la cual se considera que la distribución de dividendos por parte de una sucursal se da al vencimiento del plazo para la presentación de la Declaración Jurada Anual del IR, más allá de que se haya realizado o no tal distribución. La determinación de la cantidad a ser retenida por concepto de dividendos se hace sobre los ingresos de fuente peruana que produce la sucursal.

Ahora bien, en lo que respecta a la aplicación de la Decisión 578 de la CAN a los dividendos generados por sucursales ubicadas en Perú, tenemos que el TF señala lo siguiente:

Que en ese sentido, los dividendos distribuidos por la sucursal domiciliada en Perú hacia su empresa matriz en Colombia, se encuentran gravados con el Impuesto a la Renta a los dividendos, ya que el Perú se encuentra autorizado por la Decisión 578 a gravar las rentas que se producen en su territorio. En concordancia con lo anterior, el país beneficiario con la distribución de los dividendos (Colombia) no podrá gravarlos en cabeza de la sociedad receptora, cumpliéndose de esta forma el objetivo de evitar la doble tributación de unas mismas rentas, regulado en el artí- culo 1 de la Decisión 578. (Resolución del Tribunal Fiscal 11125-5-2019, 2019).

Continúa el citado pronunciamiento considerando los siguientes argumentos:

Que a mayor sustento, se debe señalar que cuando el artículo 11 de la Decisión 578 dispone que los dividendos «solo» se gravan en el país miembro que los distribuye, se refiere a que los dividendos se gravan en un solo país, y no en qué momento o situación se consideran distribuidas las utilidades. En tal sentido, la Decisión 578 no ha establecido en qué casos se consideran distribuidos los dividendos, razón por la cual las normas internas de los países miembros tienen la potestad de regular tal aspecto, conforme con el artículo 3 de la referida Decisión.

Que por todo lo expuesto, contrariamente a lo señalado por la recurrente, para efectos de determinar la obligación tributaria sustancial respecto del Impuesto a la Renta a los dividendos que corresponden a su empresa matriz en Colombia, procede aplicar la Decisión 578 y la norma tributaria interna; por ende, se concluye que la ficción legal establecida en el inciso e) del artículo 56 de la Ley del Impuesto a la Renta complemente lo establecido en el artículo 11 de la Decisión 578 conforme a los argumentos expuestos en la presente resolución. (Resolución del Tribunal Fiscal 11125-5-2019, 2019).

Asimismo, tenemos que Hernández Berenguel (2001) señala lo siguiente:

Sin embargo, la norma contenida en el segundo párrafo del inciso e) del artículo 
56 de la LIR debe ser entendida como la solución especial dada por el legislador respecto de cuándo se percibe el dividendo por la casa matriz o titular del exterior. Al efecto, se considera percibido el dividendo - la ley menciona la frase «se entenderán distribuidas las utilidades»_ en la fecha de vencimiento del plazo para la presentación de la declaración jurada anual del Impuesto a la Renta de la sucursal u otro tipo de establecimiento permanente.

Así, pues, corresponde a las sucursales ejercer la función de agentes de retención respecto a los rendimientos que son imputables a sus matrices, las cuales en tanto estén domiciliadas en países conformantes de la CAN no estarán sujetos a gravamen alguno por concepto de IR respecto a dichos dividendos. Ello, en tanto las sucursales acrediten su condición de domiciliadas en Perú para efectos de la aplicación de la Decisión 578 mediante el correspondiente Certificado de Residencia.

Debemos señalar que, en este extremo, la retención se aplica respecto a las rentas generadas por las matrices de las sucursales domiciliadas en Perú como consecuencia de la inversión efectuada mediante estas últimas.

No debemos confundir los dos supuestos de atribución de rentas analizados dentro del presente trabajo. En un extremo tenemos las rentas de fuente peruana obtenidas por las sucursales domiciliadas en Perú, sobre las cuales nuestro país únicamente grava las rentas producidas en su territorio, mas no las que las sucursales pudieran obtener en el extranjero; $y$ por el otro lado están los dividendos, que son los resultados de las inversiones efectuadas por las matrices en las sucursales, teniendo estas matrices la condición de contribuyentes respecto a dichos ingresos y las sucursales únicamente la condición de deudores tributarios al configurarse como agentes de retención, siendo que en este último caso los dividendos solo se encuentran afectos en Perú, en aplicación del artículo 11 de la Decisión 578 previamente citado.

Ahora bien, en este extremo cabe analizar cuál es el tratamiento aplicable a las rentas de fuente extranjera obtenidas en otro país miembro de la CAN por las sucursales domiciliadas en Perú, cuya matriz está en algún otro territorio de la CAN. Al respecto, la Administración Tributaria, analizando los alcances del inciso e) del artículo 56 de la LIR, ha señalado lo siguiente:

Agrega dicho artículo que en el caso de sucursales u otro tipo de establecimientos permanentes de personas jurídicas no domiciliadas se entenderán distribuidas las utilidades en la fecha de vencimiento del plazo para la presentación de la declaración jurada anual del Impuesto a la Renta, considerándose como monto de la distribución, la renta disponible a favor del titular del exterior; siendo que la base de cálculo comprenderá la renta neta de la sucursal u otro tipo de establecimiento permanente incrementada por los ingresos por intereses exonerados y dividendos $\mathrm{u}$ otras formas de distribución de utilidades u otros conceptos disponibles, que hubiese generado en el ejercicio menos el monto del impuesto pagado conforme al artículo anterior. (Sunat, Informe 066-2014-SUNAT/4B0000, 2014).

Del pronunciamiento de la Administración Tributaria podemos inferir que, si bien resulta aplicable la retención sobre los dividendos generados por las sucursales domiciliadas 
en Perú, el cálculo para su determinación se realiza sobre la renta neta obtenida por la sucursal más intereses exonerados y dividendos u otras formas de distribución de utilidades u otros conceptos disponibles (siempre que sean ingresos de fuente peruana), pues las rentas de fuente extranjera que pueda obtener una sucursal se constituyen como ingresos inafectos para la determinación del IR en Perú. Esto quiere decir que los mismos no forman parte de la base sobre la cual se aplica la presunción de distribución de dividendos.

Debemos aclarar que, en este caso, las rentas de fuente extranjera de las sucursales domiciliadas en Perú no se constituyen como ingresos exonerados para este EP, sino más bien como inafectos pues la norma tributaria los excluye del ámbito de aplicación del IR, al no existir vinculación entre estos y nuestro país como fuente.

En el caso de que una sucursal domiciliada en Perú genere ingresos en otro país miembro de la CAN, estos no se constituyen como exonerados en nuestro país pues dicha calificación resulta atribuible únicamente, según la Decisión 578, a los ingresos que sean susceptibles de gravamen conforme a la legislación interna de Perú, lo cual no resulta aplicable en este caso ya que nuestra legislación establece expresamente que las sucursales en Perú tributan en nuestro país solamente por las rentas de fuente peruana, dejando fuera del ámbito de aplicación del IR a las rentas de fuente extranjera.

Aunado a ello tenemos que las rentas obtenidas en otro país de la CAN por una sucursal domiciliada en Perú, solamente se encuentran gravadas en aquel país donde se encuentre la fuente de dicho ingreso, por lo que admitir que las rentas de fuente extranjera producidas en otro país miembro de la CAN también deben ser consideradas para el cálculo de la renta neta sobre la cual se aplica la retención por concepto de dividendos, implica una desnaturalización del espíritu de la Decisión 578. Ello en tanto que se reconocería como válido que un ingreso gravado en un primer momento en el país donde se encuentra la fuente productora sea susceptible de una afectación posterior, cuando se determine la base sobre la cual se aplica la presunción de distribución de dividendos prevista en la LIR. Esto quiere decir que, en el supuesto negado que este razonamiento sea aceptado, se estaría admitiendo que estos ingresos sean sometidos a una doble imposición, lo cual es contrario a las disposiciones de la Decisión 578.

Habiendo dicho ello, las rentas de fuente extranjera que obtenga una sucursal domiciliada en Perú, cuya matriz está en otro país de la CAN, no deberá considerar para efectos del cálculo de la retención por concepto de dividendos a las referidas rentas, por considerarse inafectas del IR para la normativa peruana.

Para concluir, señalamos que el tratamiento descrito en los párrafos precedentes para las rentas de fuente extranjera que obtenga una sucursal domiciliada en Perú resultará aplicable indefectiblemente, para efecto de establecer la base sobre la cual se aplica la retención por concepto de dividendos. Esto sin importar el país de domicilio de la matriz (puede ser miembro de la CAN o no), pues las rentas de fuente extranjera de estas entidades se consideran como inafectas para nuestro ordenamiento, y por ello no resultan susceptibles de computarse para el cálculo de la base sobre la cual se aplicará la retención por concepto de dividendos. 


\section{Conclusiones}

La Decisión 578 restringe la posibilidad de que el ingreso generado por un contribuyente domiciliado en un país de la CAN, en otro de los territorios de los países conformantes de este convenio, se encuentre sujeto a gravamen en dos oportunidades, pues la regla prevista en la Decisión 578 es que los ingresos se graven únicamente en el país donde está ubicada la fuente de estos.

La normativa del IR peruana ha establecido una ficción por la cual se le otorga personería jurídica a las sucursales que desarrollan actividades dentro del territorio peruano, con lo cual, frente al fisco peruano, estas entidades adquieren derechos y obligaciones en forma independiente a la de su matriz.

Conforme a una interpretación sistemática de la Decisión 578 y la normativa del IR peruana, no existe riesgo de doble imposición respecto a las rentas que produzcan sucursales, pues estas solamente están gravadas en Perú por sus rentas de fuente peruana, no existiendo la posibilidad de que nuestro país pretenda gravar un ingreso de las sucursales generado en el extranjero. Sin embargo, se deberá acreditar que la renta tiene su fuente en Perú y presentar el correspondiente Certificado de Residencia, para que el país donde se encuentre la matriz considere a estos ingresos como exonerados.

En lo que se refiere a los dividendos distribuidos por una sucursal ubicada en Perú, cuya matriz está domiciliada en otro de los países de la CAN, tenemos que tal distribución se encuentra afecta a IR solamente en Perú, debiendo considerarse como un ingreso exonerado en el país donde esté ubicada la matriz. Se debe sustentar el domicilio de la sucursal mediante el Certificado de Residencia.

Las rentas de fuente extranjera generadas en algún país de la CAN, por parte de una sucursal domiciliada en Perú, no resultan computables para la aplicación de la retención por concepto de dividendos al constituirse como ingresos inafectos al IR en Perú.

\section{Referencias bibliográficas}

Comunidad Andina de Naciones [CAN]. (2004). Decisión 578.

Congreso de la República del Perú. (19 de noviembre de 1997). Ley 26887. Ley General de Sociedades.

Durán Rojo, L. (2008). Diferencias en el tratamiento de la noción de establecimiento permanente en la legislación nacional y los CDI y su consecuencia en la tributación en el Perú por rentas empresariales de sujetos no domiciliados. En I. Perú, Convenios para evitar la Doble Imposición. 
Elias Laroza, E. (2015). Derecho Societario Peruano, La Ley General de Sociedades del Perú. Lima: Gaceta Jurídica.

Fernández-Dávila Mendoza, F. (2010). Tratamiento aplicable a las sucursales y establecimientos permanentes en el extranjero de sociedades constituidas en el Perú. X Jornadas Nacionales de Tributación - IFA Perú.

Hernández Berenguel, L. (2001). Impuesto a la Renta - Dividendos. Revista del Instituto Peruano de Derecho Tributario Nro. 41, 23.

Ministerio de Economía y Finanzas [MEF]. (2017). Tribunal Fiscal. Resolución del Tribunal Fiscal 02988-1-2017, 02988-1-2017.

MEF. (2013). Tribunal Fiscal. Resolución del Tribunal Fiscal 03256-3-2013, 03256-3-2013.

MEF. (2020).Tribunal Fiscal. Resolución del Tribunal Fiscal 03701-9-2020, 03701-9-2020.

MEF. (2019). Tribunal Fiscal. Resolución del Tribunal Fiscal 11125-5-2019, 11125-5-2019.

MEF. (8 de diciembre del 2004). Decreto Supremo 179-2004-EF Texto Único Ordenado de la Ley del Impuesto a la Renta.

Pérez Montenegro, K. (2010). Tratamiento Tributario y Tratamiento Societario de las Sucursales en la Legislación Peruana. ¿Convivencia pacífica o diferencias irreconciliables entre ambas regulaciones? - Primera Parte. Derecho y Sociedad, 98.

Superintendencia Nacional de Aduanas y de Administración Tributaria [Sunat]. (2012). Informe 008-2012-SUNAT/2B0000.

Sunat. (2014). Informe 066-2014-SUNAT/4B0000.

Sunat. (2015). Informe 094-2015-SUNAT/5D0000.

Sunat. (2016). Informe 127-2016-SUNAT/5D0000.

Yáñez Salgado, L. (2010). Tratamiento de los establecimientos permanentes ubicados en el exterior de empresas domiciliadas en el Perú. Revista del Instituto Peruano de Derecho Tributario No. 49, 141. 